American Journal of Applied Sciences 9 (1): 152-157, 2012

ISSN 1546-9239

(C) 2012 Science Publications

\title{
An Initio Theoretical Study for the Electronic Spectra of $\beta$-Thioxoketones
}

\author{
${ }^{1}$ Rita S. Elias, ${ }^{2}$ Bahjat A. Saeed and ${ }^{3}$ Dhiyaa K. Muslem \\ ${ }^{1}$ Department of Pharmaceutical Chemistry, \\ College of Pharmacy, University of Basrah, Iraq \\ ${ }^{2}$ Department of Chemistry, College of Education, University of Basrah, Iraq \\ ${ }^{3}$ Open Educational College, Baghdad, Iraq
}

\begin{abstract}
Problem statement: $\beta$-thioxoketones exist as equilibrium mixtures of the tautomeric enol and enethiol forms which interconvert very rapidly by intramolecular chelate proton transfer. Accordingly their electronic spectra in the u.v.-visible region exhibit absorption bands arising from transitions within the electronic systems involved in these tautomers. Approach: The structures of several $\beta$-thioxoketones were geometrically optimized using B3LYP/cc-pVTZ, B3LYP/6-311++G (2d,p), PM2/6-311++G(2d,p) and B3LYPl6-311G(d,p) and their electronic spectra were theoretically calculated. TD-DFT, EOM-CCSD, CIS and semi empirical ZINDO methods were used to calculate the electronic spectra. Results: The spectrum of the enolic form of thiomalonaldehyde is characterized by three absorption bands at 460, 305 and $223 \mathrm{~nm}$ due to $\mathrm{H} \rightarrow \mathrm{L}, \mathrm{H}-1 \rightarrow \mathrm{L}$ and both $\mathrm{H} \rightarrow \mathrm{L}+1$ and $\mathrm{H} \rightarrow \mathrm{L}+2$ transitions. The first band is attributed to $\mathrm{n} \rightarrow \pi^{*}$ transition within the $\mathrm{C}=\mathrm{S}$ group while the others are due to transitions with the O-C = C-C $=\mathrm{S}$ conjugated system. Both TD-DFT and ZINDO methods were able to predict the electronic spectra of the molecules studied that are in very good agreement with the observed spectra. The observed spectra were agreed to large degree with calculated spectra of the enolic tautomer of the studied compounds. Conclusion: The observed spectra were agreed to large degree with calculated spectra of the enolic tautomer of the studied compounds.
\end{abstract}

Key words: Electronic spectra, electron density difference, electrostatic potential difference, theoretical program package, qualitatively similar, intramolecular chelate

\section{INTRODUCTION}

$\beta$-thioxoketones are well known compounds due to their tautomerism and in solvent spectroscopic studies had shown that they exist exclusively or preponderantly as equilibrium mixtures of the tautomeric enol (HO$\left.\mathrm{CR}^{1}=\mathrm{CH}-\mathrm{CR}^{2}=\mathrm{S}\right)$ and enethiol $\left(\mathrm{HS}-\mathrm{CR}^{1}=\mathrm{CH}-\mathrm{CR}^{2}=\right.$ $\mathrm{O}$ ) forms, which interconvert very rapidly by intramolecular chelate proton transfer. Meanwhile, no evidence has been found for the existence of the thioxoketone tautomer $\left(\mathrm{S}=\mathrm{CR}^{1}-\mathrm{CH}_{2}-\mathrm{CR}^{2}=\mathrm{O}\right)$ form (Carlasen and Duus, 1980; Jorgensen et al., 1981; Saeed and Elias, 2011). The presence of strong intramolecular hydrogen bond that adjoins hydroxylic and ketonic oxygen and sulfur centers markedly stabilizes the enolic tautomers causing them to dominate over their diketo counterparts under ambient, isolated-molecule conditions (Nguyen et al., 2006; Andersen et al., 2000; Posokhov et al., 2001) as is the case of their structurally related analogues, $\beta$-diketones (Yamabe et al., 2004; Chatterajee et al., 2010). Accordingly they are of particular interest for studies of tautomerism and intramolecular hydrogen chelating properties (Gonzalez et al., 1999; Gonzalez et al., 1997). In this conjunction tautomeric and photochromic behavior (Hansen et al., 2007; Goeski et al., 2007) are among the most conducted studies on these compounds. The absorption spectra of the aromatic derivatives characterized by four absorption maxima in the u.v.visible region, located at ca. 265, 330, 415 and $520 \mathrm{~nm}$. Due to the presence of the tautomeric mixture these bands are supposed to arise from transitions involving the chromofors $\mathrm{ArC}=\mathrm{C}, \mathrm{ArC}=\mathrm{O}, \mathrm{ArC}=\mathrm{S}, \mathrm{S}-\mathrm{C}=\mathrm{CC}$ $=\mathrm{O}$ and $\mathrm{S}=\mathrm{CC}=\mathrm{C}-\mathrm{O}$. Thioacetylacetone exhibits two absorption bands at 296 and $355 \mathrm{~nm}$. Jorgensen et al. (1981) were the first to investigate the electronic absorption spectra of $\beta$-thioxoketones both experimentally and theoretically. In their theoretical

Corresponding Author: Rita S. Elias, Department of Pharmaceutical Chemistry, College of Pharmacy, University of Basra, Iraq 
study using CNDO/S-CI procedure the enol and the enthiol tautomer were predicted to exhibit bands at 339 and $304 \mathrm{~nm}$ respectively. In addition they gave theoretical rationale for the substituent's effect on the absorption spectra. In the presence of much more accurate theoretical methods and programs it is important to review the electronic absorption spectra of these important compounds. In this work we investigate the electronic absorption spectra of $\beta$-thioxoketones and the rule of the substituent on them.

\section{MATERIALS AND METHODS}

The observed electronic spectra were taken from previously published works (Carlasen and Duus, 1980). The quantum chemical calculations were performed with the Firefly program. Geometrical optimizations for thiomalonaldehyde were carried out using Density Functional Theory (DFT) method at B3LYP/6-311++G $(2 \mathrm{~d}, \mathrm{p}) \mathrm{B} 3 \mathrm{LYP} / \mathrm{cc}-\mathrm{pVTZ}$ and levels of theory. For all other molecules geometry optimization were done at B3LYP/6-311++G(d,p) level. B3LYP refers to the combination of functional hybrid exchange of Becke with functional correlation gradient of Lee and Yang. For the same level of theory, vibrational frequencies for all molecules were calculated to verify that the structure converged to a minimum using the zero imaginary frequencies criterion natural. Excited states were done using DT-DFT, EOM-CCSD/MP2 and CIS/MP2 methods. The semi empirical ZNDO method was employed using the ORCA theoretical program package.

\section{RESULTS}

The calculated electronic properties are shown in Fig. 1. The electronic spectra for both thione and thiol tautomers of thiomalonaldehyde at several levels of theory are gathered in Table 1. Figure 1 shows the calculated HOMO, LUMO, electron density difference and electrostatic potential difference for enol tautomer in thiomalonaldehyde. The observed and theoretically calculated electronic spectra for thioacetylacetone and thiobenzoylacetones are gathered in Table 2. Table 3 gathered the observed and theoretically calculated spectra of thiodibenzoylmethanes at TD-DFT and ZINDO methods.

\section{DISCUSSION}

Figure 1 shows the structural properties of the two most stable tautomers of thiomalonaldehyed, namely, enol and enethiol tautomers calculated at B3LYP/6$311++\mathrm{G}(2 \mathrm{~d}, \mathrm{p})$ and B3LYP/cc-pVDZ levels of theory. The calculated energies of the enol at the two levels are -590.20841798 and -590.22854808 hartrees respectively while those for the enethiol are 590.20463800 and -590.22427322 hartrees respectively show that the enol tautomer is more stable than the enethiol. The calculated bond lengths and bond angles are apparently similar for both levels. The calculated bond lengths for the $\mathrm{C}=\mathrm{O}$ groups are 1.225 and 1.226 $\AA$ at the B3LYP/cc-pVDZ and B3LYP/6-311++G(2d,p) levels are in very good agreement with that measured for hexafluoroacetylacetone by single crystal X-ray diffraction which was $1.227 \AA$. This gives reliability for these methods when used to study the electronic properties of such systems.

The calculated spectra of the two tautomers by the Time Dependent DFT, EOM-CCSD and CIS methods (Table 1) show that despite the three methods are agree in the main trend in that the absorption bands of the enol are at longer wavelength than the enethiol, the CIS method is in disagreement with first two methods in predicting the electronic spectra for both tautomers. The spectra will discuss on the basis of the TD-DFT results which predict three bands for them. The shortest bands at wavelengths 223 and $218 \mathrm{~nm}$ are of the same origin $(\mathrm{H} \rightarrow \mathrm{L}+1$ and $\mathrm{H} \rightarrow \mathrm{L}+2)$ while the long and the middle bands which arise at 485 and $305 \mathrm{~nm}$ in the enol and at 355 and $287 \mathrm{~nm}$ in the enethiol are of different origins. In the enol they are $\mathrm{H} \rightarrow \mathrm{L}$ and $\mathrm{H}-1 \rightarrow \mathrm{L}$ while they $\mathrm{H}$ $1 \rightarrow \mathrm{L}$ and $\mathrm{H} \rightarrow \mathrm{L}$ transitions respectively. The positions (485 and $355 \mathrm{~nm})$ and the oscillator strengths $(0.0002$ and 0.0006) of the long bands in both tautomers suggests that they are arising due to $n \rightarrow \pi^{*}$ transitions within the $\mathrm{C}=\mathrm{S}$ and $\mathrm{C}=\mathrm{O}$ chromofors.

In order to support that this band is due $n \rightarrow \pi^{*}$ transition in the enol tautomer, the electron density difference and the Electrostatic Potential Difference surfaces were calculated and are shown in Fig. 2. As shown in Fig. 2 the HOMO is localized to the plane of the molecule and is non-bonding molecular orbital. Meanwhile the LUMO is perpendicular to the plane of the molecule and is and is a combination of the $p_{z}$ atomic orbital on the sulfur and carbon atoms. The LUMO shows relatively larger contribution on the carbon-end of the molecule and smaller contribution from the sulfur's $\mathrm{p}_{\mathrm{z}}$ atomic orbital. On the electron density difference surface the blue color represents positive electron density difference while the red color represents negative electron density difference. 
Am. J. Applied Sci., 9 (1): 152-157, 2012

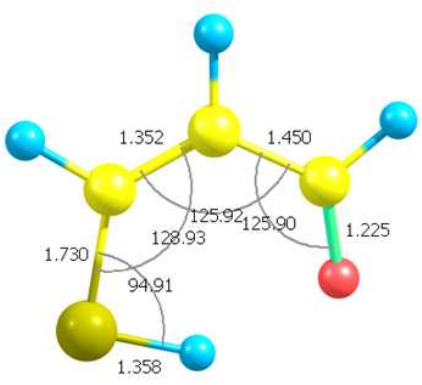

(a)

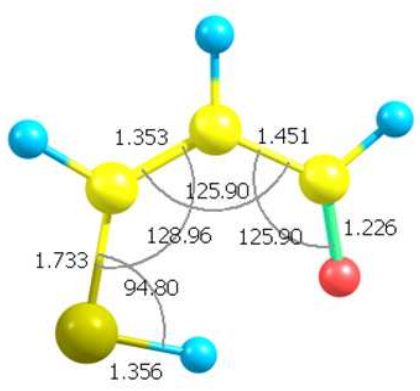

(b)

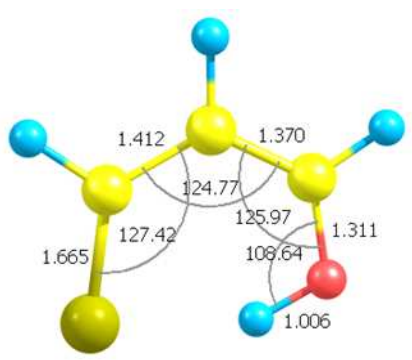

(c)

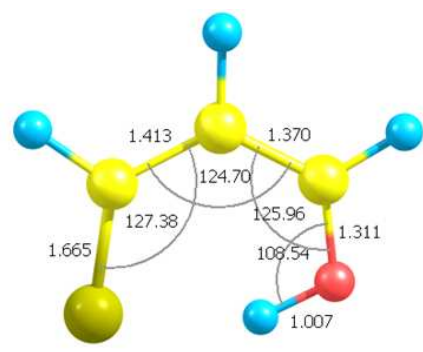

(d)

Fig. 1: The structural properties in the enol and enethiol tautomers of thiomalonaldehyde at calculated at the B3LYP/cc-pVTZ and B3LYP/6-311++G (2d,p) levels of theory (a) B3LYP/cc-pVTZ(b) $\mathrm{B} 3 \mathrm{LYP} / 6-311++\mathrm{G}(2 \mathrm{~d}, \mathrm{p})$ (c) B3LYP/ccpVTZ(d) B3LYP/6-311++G(2d,p)

The electron density has increased in the $n \rightarrow \pi^{*}$ transition and shows a relatively large increase on the carbon atom which is furthermore, perpendicular to the plane of the molecule. It is also clear that the negative electron density indicates that the electron density is coming from an in-plane region mainly around the sulfur atom. As electronic transition takes place the electron density will altered accordingly leading to change in the electrostatic potential. In the electrostatic potential difference surface Fig. 2 the red color means an increase in the electron density while the blue color means a decrease in the electron density. The surface gives a further indication that the electron density shifted from in-plane near the sulfur to out-of-the-plane near the carbon.

The remaining bands are due to transitions within the HO-C = C-C = S and HS-C = C-C = O conjugated systems. At the TD-DFT level the calculated bands for the enol are 485, 305 and $223 \mathrm{~nm}$ while those calculated for the enethiol are at 355, 287 and $218 \mathrm{~nm}$. The large difference of $130 \mathrm{~nm}$ between the longer bands of the tautomer could be rationalize on the basis that the ionization potential of sulfur is much lower than for oxygen, which shows that the lone pair electrons on sulfur are much less firmly held than on oxygen. The relatively high energy the sulfur $\mathrm{n}$ orbital thus produces a bathochromic shift. The difference between the middle bands in the tautomers is much smaller $(18 \mathrm{~nm})$ since these bands arise due to transitions within the $\mathrm{HO}-\mathrm{C}=\mathrm{C}-\mathrm{C}=\mathrm{S}$ and $\mathrm{HS}-\mathrm{C}=\mathrm{C}-\mathrm{C}$ $=\mathrm{O}$ systems which are of relatively comparable energies.

The theoretically calculated spectra ate the DTDFT and ZINDO methods as well as the experimental spectra for thioacetyleacetone and thiobenzoylacetones are shown in Table 2 . The calculated wavelengths by the two methods are in good agreement with experimental wavelengths. Both methods are able to determine the substituent effect successfully. The experimental spectrum of thioacetylacetone includes a band at $355 \mathrm{~nm}$, when compared to the calculated spectra of the enol $(313 \mathrm{~nm})$ and enethiol $(284 \mathrm{~nm})$ tautomers in this compound it could be concluded that the experimental spectrum is represent that of the enol tautomer. It has been shown that substitution effect on the spectra of $\beta$-thioxoketones depends on at which side the substitution takes place. Substitution at the $\mathrm{C}=\mathrm{O}$ side produces larger red shift than at $\mathrm{C}=\mathrm{S}$ side Table 2 . This is predicted well theoretically by both methods. According to ZINDO results Table 2 introducing a phenyl at the $\mathrm{C}=\mathrm{O}$ side of thioacetylacetone shifts its calculated band by 35 ( $\mathrm{nm}$ from $352-387 \mathrm{~nm}$ ). The experimental shift is $34 \mathrm{~nm}$ only. On the other hand the experimental red shift produced at introducing a phenyl ring at the $\mathrm{C}=\mathrm{S}$ side is $19 \mathrm{~nm}$ and the calculated shift by ZINDO method is $5 \mathrm{~nm}$ which show the same trend. 
Am. J. Applied Sci., 9 (1): 152-157, 2012

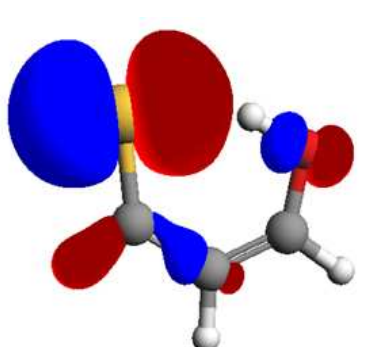

(a)

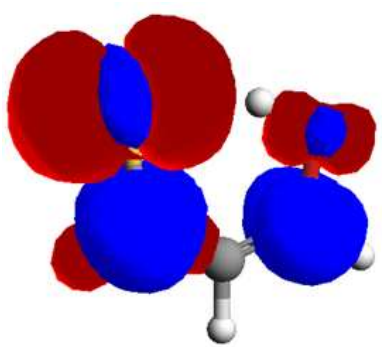

(b)

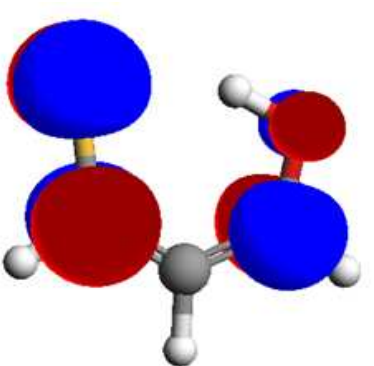

(b)

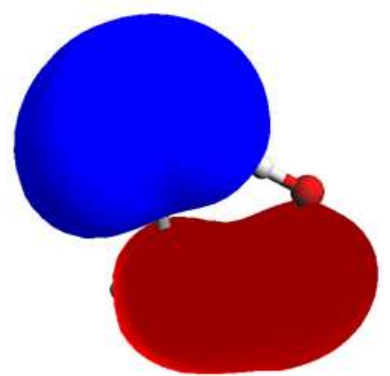

(d)
Fig. 2: HOMO, LUMO, electron density difference and electrostatic potential difference for enol tautomer (a) HOMO (b) LUMO (c) Electron density difference (d) Electrostatic potential difference
Table 1:Theoretically calculated electronic spectra of enol and enethiol tautomers at several methods using $6-311++\mathrm{G}(2 \mathrm{~d}$, p) bases set

\begin{tabular}{|c|c|c|c|c|c|c|}
\hline \multirow[b]{3}{*}{ Tautomer } & \multicolumn{6}{|c|}{ Theoretical level } \\
\hline & \multicolumn{4}{|c|}{ TD/B3LYP } & \multirow[b]{2}{*}{$\begin{array}{l}\text { EOM-CCSD/ } \\
\text { MP2 } \\
\lambda, \mathrm{nm}\end{array}$} & \multirow[b]{2}{*}{$\begin{array}{l}\text { CIS - } \\
\text { MP2 } \\
\lambda, \mathrm{nm}\end{array}$} \\
\hline & $\begin{array}{l}\text { State } \\
\text { excited }\end{array}$ & Coefficient & $\begin{array}{l}\text { Oscillator } \\
\text { strength }\end{array}$ & $\lambda, \mathrm{nm}$ & & \\
\hline \multirow[t]{4}{*}{$\overline{\text { Enol }}$} & $\mathrm{H} \rightarrow \mathrm{L}$ & 0.70654 & 0.0002 & 485 & 460 & 356 \\
\hline & $\mathrm{H}-1 \rightarrow \mathrm{L}$ & 0.70089 & 0.2113 & 305 & 310 & 269 \\
\hline & $\mathrm{H} \rightarrow \mathrm{L}+1$ & 0.69197 & 0.0238 & 223 & 201 & 164 \\
\hline & $\mathrm{H} \rightarrow \mathrm{L}+2$ & 0.10991 & & & & \\
\hline \multirow[t]{4}{*}{ Enethiol } & $\mathrm{H}-1 \rightarrow \mathrm{L}$ & 0.70237 & 0.0006 & 355 & 330 & 263 \\
\hline & $\mathrm{H} \rightarrow \mathrm{L}$ & 0.69629 & 0.2078 & 287 & 267 & 230 \\
\hline & $\mathrm{H} \rightarrow \mathrm{L}+1$ & 0.63058 & 0.0000 & 218 & 204 & 195 \\
\hline & $\mathrm{H} \rightarrow \mathrm{L}+2$ & 0.29715 & & & & \\
\hline
\end{tabular}

Table 2: Observed and theoretically calculated spectra of Thioacetylacetone and thiodybenzoylacetones

\begin{tabular}{|c|c|c|c|c|c|c|c|}
\hline \multicolumn{2}{|c|}{ Compound } & \multicolumn{4}{|c|}{ TD-B3LYP/6-311++G (d, p) } & \multirow[b]{2}{*}{$\begin{array}{l}\text { ZINDO } \\
\lambda, \mathrm{nm}\end{array}$} & \multirow[b]{2}{*}{$\begin{array}{l}\text { Observed } \\
\lambda, \mathrm{nm}\end{array}$} \\
\hline $\mathrm{R}^{1}$ & $\mathrm{R}^{2}$ & $\begin{array}{l}\text { Excited } \\
\text { state }\end{array}$ & Coefficient & $\lambda, \mathrm{nm}$ & $\begin{array}{l}\text { Oscillator } \\
\text { strength }\end{array}$ & & \\
\hline$\overline{\mathrm{CH}_{3}}$ & $\mathrm{CH}_{3}$ (thione) & $\mathrm{H} \rightarrow \mathrm{L}$ & 0.70182 & 313 & 0.2331 & 352 & $355^{\mathrm{a}}$ \\
\hline $\mathrm{CH}_{3}$ & $\mathrm{CH}_{3}$ (thiol) & $\mathrm{H} \rightarrow \mathrm{L}$ & 0.63904 & 284 & 0.2117 & 269 & --- \\
\hline $\mathrm{CH}_{3}$ & $\mathrm{Ph}$ & $\mathrm{H} \rightarrow \mathrm{L}$ & 0.70599 & 361 & 0.5256 & 387 & $389^{\mathrm{b}}$ \\
\hline $\mathrm{Ph}$ & $\mathrm{CH}_{3}$ & $\mathrm{H} \rightarrow \mathrm{L}$ & 0.67226 & 334 & 0.1517 & 360 & $374^{\mathrm{b}}$ \\
\hline $\mathrm{Ph}$ & 4- $\mathrm{MeC}_{6} \mathrm{H}_{4}$ & $\mathrm{H} \rightarrow \mathrm{L}$ & 0.69766 & 361 & 0.5965 & 389 & $392^{\mathrm{b}}$ \\
\hline $\mathrm{Ph}$ & $4-\mathrm{MeOC}_{6} \mathrm{H}_{4}$ & $\mathrm{H} \rightarrow \mathrm{L}$ & 0.70578 & 362 & 0.5909 & 391 & $399^{\mathrm{b}}$ \\
\hline $\mathrm{Ph}$ & 4- $\mathrm{BrC}_{6} \mathrm{H}_{4}$ & $\mathrm{H} \rightarrow \mathrm{L}$ & 0.68307 & 367 & 0.6497 & 387 & $390^{\mathrm{b}}$ \\
\hline
\end{tabular}

Table 3: Calculated and observed spectra of thiodibenzoylmethanes

\begin{tabular}{|c|c|c|c|c|c|c|c|}
\hline \multirow[b]{2}{*}{$\mathrm{R}^{1}$} & \multirow[b]{2}{*}{$\mathrm{R}^{2}$} & \multicolumn{4}{|c|}{ TD-B3LYP/6-311++G (d,p) } & \multirow[b]{2}{*}{$\lambda, \mathrm{nm}$} & \multirow[b]{2}{*}{$\lambda, \mathrm{nm}^{*}$} \\
\hline & & $\begin{array}{l}\text { Oscillator } \\
\text { excited state }\end{array}$ & $\begin{array}{l}\text { ZINDO } \\
\lambda, \mathrm{nm}\end{array}$ & $\begin{array}{l}\text { observed } \\
\text { coefficient }\end{array}$ & strength & & \\
\hline \multirow[t]{5}{*}{$\mathrm{Ph}$} & \multirow[t]{5}{*}{$\mathrm{Ph}$} & $\mathrm{H}-1 \rightarrow \mathrm{L}$ & 510 & 0.70409 & 0.0001 & 655 & 515 \\
\hline & & $\mathrm{H} \rightarrow \mathrm{L}$ & 386 & 0.70044 & 0.4253 & 404 & 408 \\
\hline & & $\mathrm{H}-3 \rightarrow \mathrm{L}$ & 340 & 0.16593 & 0.3045 & 332 & 325 \\
\hline & & $\mathrm{H}-2 \rightarrow \mathrm{L}$ & & 0.67729 & & & \\
\hline & & --- & --- & --- & --- & 296 & 262 \\
\hline \multirow[t]{6}{*}{$\mathrm{Ph}$} & \multirow[t]{6}{*}{ 4- $\mathrm{BrC}_{6} \mathrm{H}_{4}$} & $\mathrm{H}-1 \rightarrow \mathrm{L}$ & 514 & 0.70347 & 0.0001 & 663 & 520 \\
\hline & & $\mathrm{H} \rightarrow \mathrm{L}$ & 393 & 0.10023 & 0.5579 & 404 & 209 \\
\hline & & $\mathrm{H}-2 \rightarrow \mathrm{L}$ & & 0.69779 & & & \\
\hline & & $\mathrm{H}-3 \rightarrow \mathrm{L}$ & 346 & 0.17427 & 0.2864 & 335 & 328 \\
\hline & & $\mathrm{H}-2 \rightarrow \mathrm{L}$ & & 0.67373 & & & \\
\hline & & --- & --- & --- & --- & 299 & 271 \\
\hline \multirow[t]{5}{*}{$\mathrm{Ph}$} & \multirow[t]{5}{*}{$4-\mathrm{MeC}_{6} \mathrm{H}_{4}$} & $\mathrm{H}-1 \rightarrow \mathrm{L}$ & 506 & 0.70433 & 0.0001 & 639 & 515 \\
\hline & & $\mathrm{H} \rightarrow \mathrm{L}$ & 390 & 0.70013 & 0.4902 & 408 & 413 \\
\hline & & $\mathrm{H}-3 \rightarrow \mathrm{L}$ & 337 & 0.0 .1601 & 0.3018 & 332 & 323 \\
\hline & & $\mathrm{H}-2 \rightarrow \mathrm{L}$ & & 0.67815 & & & \\
\hline & & --- & --- & --- & --- & 295 & 268 \\
\hline \multirow[t]{5}{*}{$\mathrm{Ph}$} & \multirow[t]{5}{*}{$4-\mathrm{MeOC}_{6} \mathrm{H}_{4}$} & $\mathrm{H}-1 \rightarrow \mathrm{L}$ & 508 & 0.70415 & 0.0001 & 654 & 515 \\
\hline & & $\mathrm{H} \rightarrow \mathrm{L}$ & 390 & 0.69938 & 0.5016 & 408 & 423 \\
\hline & & $\mathrm{H}-3 \rightarrow \mathrm{L}$ & 326 & 0.16562 & 0.2969 & 333 & 326 \\
\hline & & $\mathrm{H}-2 \rightarrow \mathrm{L}$ & & 0.67706 & & & \\
\hline & & --- & --- & --- & --- & 296 & 245 \\
\hline \multirow[t]{5}{*}{ 4- $\mathrm{MeC}_{6} \mathrm{H}_{4}$} & \multirow[t]{5}{*}{$\mathrm{Ph}$} & $\mathrm{H}-1 \rightarrow \mathrm{L}$ & 508 & 0.70004 & 0.0001 & 646 & 520 \\
\hline & & $\mathrm{H} \rightarrow \mathrm{L}$ & 385 & 0.68301 & 0.4441 & 403 & 408 \\
\hline & & $\mathrm{H}-2 \rightarrow \mathrm{L}$ & & -0.10575 & & & \\
\hline & & $\mathrm{H}-3 \rightarrow \mathrm{L}$ & 353 & 0.68906 & 0.3561 & 343 & 340 \\
\hline & & $\mathrm{H}-2 \rightarrow \mathrm{L}$ & & 0.10059 & & & \\
\hline
\end{tabular}


Am. J. Applied Sci., 9 (1): 152-157, 2012

Table 3: Continue

\begin{tabular}{|c|c|c|c|c|c|c|c|}
\hline \multirow{6}{*}{ 4- $\mathrm{MeC}_{6} \mathrm{H}_{4}$} & \multirow{5}{*}{$4-\mathrm{BrC}_{6} \mathrm{H}_{4}$} & --- & --- & --- & -.- & 297 & 261 \\
\hline & & $\mathrm{H}-1 \rightarrow \mathrm{L}$ & 512 & 0.69997 & 0.0001 & 656 & 520 \\
\hline & & $\mathrm{H}-2 \rightarrow \mathrm{L}$ & 392 & 0.13413 & 0.5845 & 403 & 411 \\
\hline & & $\mathrm{H} \rightarrow \mathrm{L}$ & & 0.68884 & & & \\
\hline & & $\begin{array}{l}\mathrm{H}-3 \rightarrow \mathrm{L} \\
\mathrm{H}-2 \rightarrow \mathrm{L}\end{array}$ & 360 & 0.68386 & 0.33 & 347 & 346 \\
\hline & & --- & --- & --- & --- & 299 & 272 \\
\hline \multirow[t]{6}{*}{ 4- $\mathrm{MeC}_{6} \mathrm{H}_{4}$} & \multirow[t]{6}{*}{ 4- $\mathrm{MeC}_{6} \mathrm{H}_{4}$} & $\mathrm{H}-1 \rightarrow \mathrm{L}$ & 504 & 0.70219 & 0.0001 & 640 & 515 \\
\hline & & $\mathrm{H} \rightarrow \mathrm{L}$ & 389 & 0.11151 & 0.5165 & 407 & 413 \\
\hline & & $\mathrm{H}-2 \rightarrow \mathrm{L}$ & & 0.69461 & & & \\
\hline & & $\mathrm{H}-3 \rightarrow \mathrm{L}$ & 350 & 0.68789 & 0.3478 & 343 & 339 \\
\hline & & $\mathrm{H}-2 \rightarrow \mathrm{L}$ & & -0.10706 & & & \\
\hline & & --- & --- & --- & -- & 296 & 268 \\
\hline \multirow[t]{6}{*}{$4-\mathrm{MeC}_{6} \mathrm{H}_{4}$} & \multirow[t]{6}{*}{$4-\mathrm{MeOC}_{6} \mathrm{H}_{4}$} & $\mathrm{H}-1 \rightarrow \mathrm{L}$ & 506 & 0.70212 & 0.0001 & 644 & 510 \\
\hline & & $\mathrm{H} \rightarrow \mathrm{L}$ & 389 & 0.12018 & 0.5332 & 406 & 422 \\
\hline & & $\mathrm{H}-2 \rightarrow \mathrm{L}$ & & 0.693 & & & \\
\hline & & $\mathrm{H}-3 \rightarrow \mathrm{L}$ & 353 & 0.68619 & 0.3404 & 344 & 337 \\
\hline & & $\mathrm{H}-2 \rightarrow \mathrm{L}$ & & -0.1154 & & & \\
\hline & & --- & --- & --- & -- & 297 & 248 \\
\hline \multirow[t]{6}{*}{ 4- $\mathrm{MeC}_{6} \mathrm{H}_{4}$} & \multirow[t]{6}{*}{$3-\mathrm{MeC}_{6} \mathrm{H}_{4}$} & $\mathrm{H}-1 \rightarrow \mathrm{L}$ & 510 & 0.70083 & 0.0001 & 651 & 520 \\
\hline & & $\mathrm{H} \rightarrow \mathrm{L}$ & 390 & 0.18181 & 0.4357 & 403 & 412 \\
\hline & & $\mathrm{H}-2 \rightarrow \mathrm{L}$ & & 0.67617 & & & \\
\hline & & $\mathrm{H}-3 \rightarrow \mathrm{L}$ & 361 & 0.28588 & 0.027 & 344 & 335 \\
\hline & & $\mathrm{H}-2 \rightarrow \mathrm{L}$ & & 0.61117 & & & \\
\hline & & --- & --- & --- & --- & 300 & 252 \\
\hline \multirow[t]{6}{*}{$4-\mathrm{MeOC}_{6} \mathrm{H}_{4}$} & \multirow[t]{6}{*}{$\mathrm{Ph}$} & $\mathrm{H}-1 \rightarrow \mathrm{L}$ & 506 & 0.70382 & 0.0001 & 661 & 515 \\
\hline & & $\mathrm{H} \rightarrow \mathrm{L}$ & 385 & -0.1215 & 0.4692 & 404 & 407 \\
\hline & & $\mathrm{H}-2 \rightarrow \mathrm{L}$ & & 0.69525 & & & \\
\hline & & $\mathrm{H}-3 \rightarrow \mathrm{L}$ & 353 & 0.68904 & 0.3292 & 344 & 372 \\
\hline & & $\mathrm{H}-2 \rightarrow \mathrm{L}$ & & 0.1184 & & & \\
\hline & & --- & --- & --- & --- & 297 & 259 \\
\hline \multirow[t]{7}{*}{ 4- $\mathrm{MeOC}_{6} \mathrm{H}_{4}$} & \multirow[t]{7}{*}{ 4- $\mathrm{BrC}_{6} \mathrm{H}_{4}$} & $\mathrm{H}-1 \rightarrow \mathrm{L}$ & 510 & 0.65702 & 0.13061 & 661 & 520 \\
\hline & & $\mathrm{H} \rightarrow \mathrm{L}+1$ & & 0.13061 & & & \\
\hline & & $\mathrm{H} \rightarrow \mathrm{L}$ & 328 & -0.1036 & 0.6226 & 404 & 410 \\
\hline & & $\mathrm{H}-2 \rightarrow \mathrm{L}$ & & 0.66091 & & & \\
\hline & & $\mathrm{H}-3 \rightarrow \mathrm{L}$ & 273 & -0.1072 & 0.5986 & 344 & 368 \\
\hline & & $\mathrm{H}-2 \rightarrow \mathrm{L}$ & & 0.61475 & & & \\
\hline & & --- & --- & --- & --- & 297 & 264 \\
\hline \multirow[t]{6}{*}{ 4- $\mathrm{MeOC}_{6} \mathrm{H}_{4}$} & \multirow[t]{6}{*}{$4-\mathrm{MeOC}_{6} \mathrm{H}_{4}$} & $\mathrm{H}-1 \rightarrow \mathrm{L}$ & 503 & 0.6654 & 0.0001 & 649 & 510 \\
\hline & & $\mathrm{H} \rightarrow \mathrm{L}$ & 390 & 0.10617 & 0.5861 & 408 & 421 \\
\hline & & $\mathrm{H}-2 \rightarrow \mathrm{L}$ & & 0.66523 & & & \\
\hline & & $\mathrm{H}-3 \rightarrow \mathrm{L}$ & 271 & 0.62576 & 0.5749 & 342 & 365 \\
\hline & & $\mathrm{H}-2 \rightarrow \mathrm{L}$ & & 0.11621 & & & \\
\hline & & --- & --- & --- & --- & 295 & 253 \\
\hline
\end{tabular}

The electronic spectra of thiodibenzoylmethanes consist of four bands within the ranges $\lambda_{1}: 242-272, \lambda_{2}: 323-$ $378, \lambda_{3}: 407-423$ and $\lambda_{4}: 510-520 \mathrm{~nm}$ Table 3 . Theoretical calculations using the ZINDO method predicted nicely the bands $\lambda_{2}$ and $\lambda_{3}$ to be within the ranges $402-408$ and 331-372 $\mathrm{nm}$ respectively, while it is overestimated the $\lambda_{4}$ band by more than $120 \mathrm{~nm}$. On the other hand, TD-DFT method is predicted the bands $\lambda_{3}$ and $\lambda_{4}$ to be within the ranges 385-393 and 504-514 $\mathrm{nm}$ respectively. The band $\lambda_{3}$ which is an absorption arising alone from the $\mathrm{O}-\mathrm{C}=\mathrm{C}-\mathrm{C}=\mathrm{s}$ system shows shifts in consequence of variation in $\mathrm{R}^{2}$. This is interpreted [ ] on the basis of both conjugative and inductive effects.

When $\mathrm{R}^{2}$ is $\mathrm{p}-\mathrm{BrC}_{6} \mathrm{H}_{5}$ the $\mathrm{C}=\mathrm{C}-\mathrm{C}=\mathrm{S}$ system interacts strongly with the energetically high-lying $3 \mathrm{p} \pi$ bromine electrons. This is true for $\mathrm{R}^{2}=\mathrm{p}-\mathrm{MeOC}_{6} \mathrm{H}_{5}$, but in the effect will be weaker due to the less effective interaction between the relatively lower lying $2 \mathrm{p} \pi$ oxygen electrons in the methoxy group and the $\mathrm{C}=\mathrm{C}-\mathrm{C}$ $=\mathrm{S} \pi$-system. These interactions are modified by the simultaneously operating electron-withdrawing inductive effects $(\mathrm{Br}>\mathrm{MeO})$ leading to make the net effects of the substituent are qualitatively similar.

\section{CONCLUSION}

Both TD-DFT and ZINDO methods were able to predict the electronic spectra of the molecules studied that are in very good agreement with the observed spectra. The observed spectra were agreed to large degree with calculated spectra of the enolic tautomer of the studied compounds. 


\section{REFERENCES}

Andersen, B., F. Duus, S. Bolvig and P.E. Hansen, 2000. Variable temperature ${ }^{1} \mathrm{H}$ and ${ }^{13} \mathrm{C}$ NMR spectroscopic investigation of the enol-enethiol tautomerism of $\beta$-thioxoketones. Isotope effects due to deuteron chelation. J. Mol. Struct., 552: 4562. DOI: $10.1016 / \mathrm{S} 0022-2860(00) 00458-0$

Carlasen, L. and F. Duus, 1980. $\beta$-Thioxoketones. Part 6. Electronic absorption spectra of aromatic $\beta$ thioxoketones. A study of enol-enethiol tautomerism. J. Chem. Soc. Perkin Trans., 2: 17681773. DOI: 10.1039/P29800001768

Chatterajee, C., C.D. Incarvito, L.A. Burns and P.H. Vaccaro, 2010. Electronic structure and proton transfer in ground-state hexafluoroacetylacetone. J. Phys. Chem., 114: 6630-6640. DOI: 10.1021/jp101224e

Goeski, A., Y. Posokhov, B.K.V. Hansen, J. SpangetLarsen and J. Jansy et al., 2007. Photochromism in p-methylbenzoylthioacetone and related $\beta$ thioxoketones. Chem. Phys., 338: 11-22. DOI: 10.1016/j.chemphys.2007.07.030

Gonzalez, L., O. Mo and M. Yanez, 1997. High-level ab initio calculations on the intramolecular hydrogen bond in thiomalonaldehyde. J. Phys. Chem., 101: 9710-9719. DOI: 10.1021/jp970735z

Gonzalez, L., O. Mo and M. Yanez, 1999. Substituent effects on the strength of the intramolecular hydrogen bond of thiomalonaldehyde. J. Org. Chem., 64: 2314-2321. DOI: 10.1021/jo981982h
Hansen, B.K.V., A. Gorski, Y. Posokhov, F. Duus and P.E. Hansen et al., 2007. Monothiodibenzoylmethane: Structural and vibrational assignments. Vibrat. Spectrosc., 43: 5363. DOI: 10.1016/j.vibspec.2006.06.015

Jorgensen, F.S., L. Jorgensen and F. Duus, 1981. The electronic structure of $\beta$-thioxoketones. A photoelectron spectroscopic study of the enolenethiol tautomerism of thioacetylacetone and related compounds. J. Am. Chem. Soc., 103: 13501353. DOI: $10.1021 / \mathrm{ja} 00396 \mathrm{a} 008$

Nguyen, T.T., T.N. Le, P.E. Hansen and F. Duus, 2006. Preparation and structural characterization of a new class of stable thioketones: Orthohydroxythioacetophenones. Tetrahedron Lett., 47: 8433-8435. DOI: 10.1016/j.tetlet.2006.09.033

Posokhov, Y., A. Gorski, J. Spenget-Larsen, F. Duus and P.E. Hansen et al., 2001. The structure of the phototransformation product of monothiodibenzoylmethane. Chem. Phys. Lett., 350: 502-508. DOI: 10.1002/cphc.200404016

Saeed, B.A. and R.S. Elias, 2011. Intrahydrogen bonding and transition states between enol and enethiol tautomers in $\beta$-thioxoketones. Am. J. Appl. $\quad$ Sci., $\quad 8$ : 762-765. DOI: 10.3844/ajassp.2011.762.765

Yamabe, S.H., N. Tsuchida and K. Miyajima, 2004. Reaction Paths of keto-enol tautomerization of $\beta$ diketones. J. Phys. Chem., 108: 2750-2757. DOI: 10.1021/jp031243r 